\title{
Evaluation of quality of life in individuals with severe chronic motor disability: A major challenge
}

\author{
Marie-Christine Rousseau ${ }^{1, *}$, Karine Baumstarck², Thierry Billette de Villemeur ${ }^{3}$, Pascal Auquier ${ }^{2}$ \\ ${ }^{1}$ Hôpital San Salvadour (Assistance Publique Hôpitaux de Paris), Paris, France; \\ ${ }^{2}$ EA3279 Santé Publique: Maladies Chroniques et Qualité de Vie, Faculté de Médecine Timone Marseille, Paris, France; \\ ${ }^{3}$ Hôpital Trousseau (Assistance Publique Hôpitaux de Paris), Paris, France.
}

\begin{abstract}
Summary Diverse conditions causing a very heavy and chronic motor disability, such as an advanced amyotrophic lateral, advanced form of multiple sclerosis, high spinal cord injury or a lockedin syndrom, are now getting better medical care and benefit of life support technology with consequent prolonged survival. Quality of life (QoL) assessment is being considered increasingly important to globally apprehend their general well-being. However, the motor disability that affects them appears as a substantial limitation for the assessment of their QoL and consequently a major challenge for all the community that carries an interest for them. This review discussed several avenues to provide to patients and caregivers, clinicians and researchers, and health decision making authority: $i$ ) elements to determine the most appropriate QoL measure with regard to the interest of patient's point of view, the QoL instruments suitable for this category of patients and their acceptability, ii) some arguments of the clinical relevance and accuracy of QoL assessment: interpretations of the questionnaires, QoL determinants, particularity of QoL evaluation for individuals with cognitive impairment and the caregivers perceptions of patients QoL. In conclusion, evaluation of QoL in patients with severe chronic motor handicap is a challenge of major interest, with major ethical issues. It needs to use adapted QoL scales and longitudinal following because of adaptive phenomena to the degree of handicap.
\end{abstract}

Keywords: Motor handicap, quality of life, evaluation, death, caregivers

\section{Introduction}

Diverse conditions causing a very heavy and chronic motor disability, such as an advanced amyotrophic lateral (ALS), advanced form of multiple sclerosis (MS), high spinal cord injury (SCI) with subsequent tetraplegia or a locked-in syndrom (LIS), are now getting better medical care and benefit of life support technology with consequent prolonged survival. These medical advances do not prevent against collateral and important consequences on the everyday life of patients but also their caregivers, both on institutional

Released online in J-STAGE as advance publication April 11, 2016.

*Address correspondence to:

Dr. Marie-Christine Rousseau, Hôpital San Salvadour (Assistance Publique Hôpitaux de Paris), BP 30 080, 83407 Hyères cedex, France.

E-mail: marie-christine.rousseau@ssl.aphp.fr and natural (family) caregivers. Similarly to other less severe chronic conditions, evaluation of disease course and management of care, identification of specific supports may not rely only on the physical and functional disability that does not reflect all the facets that individuals consider important in their life. Many studies demonstrate that in patients with severe chronic motor disability, quality of life (QoL) does not correlate with physical function (1-4). In this context, QoL assessment is being considered increasingly important to globally apprehend the general well-being of these individuals. However, the motor disability that affects them appears as a substantial limitation for the assessment of their QoL and consequently a major challenge for all the community that carries an interest for them. This review discusses several avenues to provide to patients and caregivers, clinicians and researchers, and health decision making authorities: i) elements to determine the most appropriate QoL measure and $i i$ ) some arguments of the clinical 
relevance and accuracy of QoL assessment.

\section{Quality of life assessment in individuals with severe chronic motor disability}

\subsection{The major interest of patient's point of view}

Quality of life may be assessed from individual faceto-face interviews (unstructured or semi-structured) performed by experienced professionals. For this specific category of patients, this approach can be considered as inappropriate because of a very limited verbal communication and a major motor handicap. For these patients, communication may imply the use of alternative communication as eye blinks or eye movements or communication boards, and upper limbs disability may imply the help of electronic communication devices or the help of someone else. While these particularities prevent the implementation of any types of interviews, using measures as standardized and self-reported questionnaires may be an interesting alternative approach that is commonly used for individuals without severe chronic motor disability.

Quality of life may be assessed by a proxy or a caregiver in specific situations, as parents for children too young for answering a questionnaire or natural caregivers for patients with important cognitive dysfunction. For patients with severe chronic motor disability, the QoL was often assessed by their families and by caregivers in the majority of studies. They often felt that the patient presents a very degraded QoL. Several studies indicate that patients with chronical severe motor handicap and their caregivers or families do not always hold the same ideas and beliefs on patient's treatment course and end-of-life decisions (4). They may consider that patient's QoL is so poor their lives are not worth sustaining. This point is of major interest because decisions of life terminating measures are often influenced by professional or natural caregivers. The QoL of people in heavy motor disabilities is often subject to representations of caregivers whose patients depend: healthy individuals, caregivers, family support and health professionals frequently underestimate the QoL of the patients assuming that QoL in severely handicapped people is very poor (4-7). But some studies showed that these persons may report relatively satisfactory QoL levels that are stable over time $(8,9)$. The $\mathrm{QoL}$ is sometimes better than patients presented other disabilities, such as patients with new diagnoses of Alzheimer's disease (10) and patients with facial prostheses (11). These findings, suggesting that life with severe chronic motor disability is worth living in contrast to the general and widespread opinions, highlight the importance to directly assess the report of the patients. Indeed, the management of these diseases, raising ethical questions, should be supported by the QoL assessment of the individuals themselves.

\subsection{A large variety of quality of life instruments}

It is important to have robust, valid, reliable, and widespread measures. Many questionnaires, specific and generic, are proposed to assess QoL. Generic instruments are generally used to compare QoL across different populations, while disease-specific instruments focus on particular health problem and seem more sensitive for detecting changes $(12,13)$.

Many studies described QoL for severe chronic motor disability using generic QoL questionnaires:

- The 36-item short form (SF36) is a generic questionnaire used worldwide (14) for which norms are available (15). SF36 was used among patients with severe MS (16), LIS (17), ALS or SCI $(18,19)$.

- The Sickness Impact Profile (SIP) (20) may be used in patients with chronic motor handicap $(21,22)$ but this scale is less effective in assessing psychosocial wellbeing than physical status. Trail et al. demonstrated for patients with ALS that important domains of QoL do not correlate with physical functional abilities as measured by generic and function-based instruments such as SIP (4).

- The World Health Organization Quality of Life (WHOQOL-BREF) questionnaire is a generic questionnaire used worldwide $(23,24)$ and has been used in several studies concerning motor disabled patients $(25,26)$.

- The Anamnestic Comparative Self-Assessment (ACSA) provides an overall assessment of QoL based on the patient's memories of the best period in their life before the disease and their worst period (27). It is an instrument particularly adapted to populations with severe chronic motor disability and very limited verbal communication due to the rapid passation time (less than 5 minutes) $(27,28)$. ACSA has demonstrated its feasibility among LIS patients $(9,29)$.

Two other generic instruments are largely used in these specific populations: the McGill scale and the Schedule for the Evaluation of Individual QoL-Direct Weighting (SEIQoL-DW). These two instruments are individualized QoL measures investigating existential and psychological factors. These factors appear to play a significant role in the QoL of these patients such as faith, dignity, maintain of identity, and spirituality. It demonstrated improvements in QoL areas despite loss of physical function; they are thus very fitted for patients with heavy motor handicap.

- The SEIQoL-DW is derived from the original SEIQoL (30-32). The SEIQoL-DW is an interesting QoL generic instrument using a semi-structured interview to collect data allowing patients to spontaneously and freely nominate areas that appear important in their life. SEIQoL-DW is very fitted and useful for patients with heavy motor handicap $(3,21,33-36)$. 
- The McGill scale includes physical and psychological aspects. But the physical and functional aspects are less pronounced, while existential domains are emphasized. It has been used in patients with ALS and has a good validity $(1,25,37)$.

Several authors reported that generic instrument accurate not well estimation of patient's $\operatorname{QoL}(2,38)$. Some disease-specific questionnaires were used on subgroups of severe chronic motor disability. The Amyotrophic Lateral Sclerosis Assessment Questionnaire (ALSAQ-40) was designed for ALS patients (39) but is rather heavily weighted toward physical function. A large number of MS-specific QoL instruments are available (the Multiple Sclerosis Quality of Life Index (MSQLI) (40), the Multiple Sclerosis Impact Scale (MSIS-29) (41), the Multiple Sclerosis International Quality of Life questionnaire (MusiQoL) (42) but not really adapted for advanced form of MS presenting severe chronic motor disability.

To our knowledge no specific questionnaire designed for severe chronic motor disability is available. The content of a specific questionnaire relies in general on either the literature or experts to determine the domains and concerns that are important for the individuals, although it is now generally accepted that the content of QoL measures should be directly derived from affected individuals (43). The development of this kind of QoL questionnaire should be a major project for researchers, health care workers, patients, and families.

\subsection{The acceptability of the questionnaire}

A great asset of a QoL questionnaire is its acceptability. It concerns the ergonomics of the questionnaire, the length of the questionnaire, and the content of the questionnaire. Due to severe chronic motor disability (leading to communication and movements' limitation), questionnaires should have specific attributes to be used among patients with:

i) The need of availability of e-form QoL validated questionnaires: a potential opportunity for questionnaire development exists in the growing use of electronic measures. For patients with severe chronic motor disability it's a really challenge to provide e-forms that can be used with computer stations and handheld devices. In cases where patients are equiped with computer interface systems, this allows them to dispense with the assistance of a third person. It is well documented that the presence and assistance of a third person may influence the responses of patients who over- or under-estimates the QoL compared to questionnaires completed alone.

ii) The need of availability of short questionnaires to take account the difficulties of concentration, or tiredness, or other cognitive dysfunction that may affect the individuals. In our personal experience, a quadriplegic (C1) patient or a LIS patient needs about 45 minutes to fullfill the SF36 scale (unpublished data) that it is not apropriate with a clinical routine evaluation. Questionnaires intended for use should be as brief as possible. It highlights the interest of using uniscales giving one overall QoL score, easier to use rather than longer multi-items scales. Future challenges now focus on the concept of computer adaptative testing. The number of items can be reduced substantially to target questions through an iterative process in which responses determine which items are subsequently presented. This approach requires development and validation of algorithms in addition to development and validation of the original questionnaire (44).

iii) The specificities of some questions could make the person feel bad about his/her physical restriction and may suggest a QoL-assessment nocebo effect (i.e., negative expectations that derived from the clinical encounter and led to poor health outcomes (45). Measuring QoL may cause 'side effects' through the exploration of sensitive subjects, thereby generating new expectations for the clinicians on the part of the patients (46).

\section{Arguments of the clinical relevance and accuracy of quality of life assessment}

\subsection{Assistance to interpret quality of life scores}

In some specific situations, clinicians can be perplexed when interpreting QoL scores.

The first difficulty encountered when interpreting a QoL score for clinicians is the lack of norms values. The SF36 or the WHOQOL-BREF, generic instruments, are commonly used due to the availability of normative data from healthy adults (47). It is rare to have scores according to sex and gender. Additionally, it becomes imperative to produce norms for the most popular instruments. Aggregating datasets may contribute to produce valid and robust norms. Each patient would be compared to norms.

A second difficulty expressed by clinicians is the interpretation of QoL measures in longitudinal studies because QoL, self-reported by the patient, might be influenced by psychological phenomena such as adaptation to illness. It has been previously observed that patients' subjective QoL is not related to physical impairments; this observation agrees with previous studies of different motor neuron disorders $(1,2,25,34,38,48-53)$, SCI patients (54), and LIS patients $(5,9,49,53,55)$. This illustrates the "disability paradox" reported by Albrecht and Devlieger $(51,56)$.

Albrecht \& Devliger stated that QoL is dependent on establishing and monitoring a harmonious set of relationships with the person's social context and external environment (56). Most people with long-term chronic condition do not mention physical disability 
as their primary concern but rather their psychological and emotional well-being (57). This lack of association between objective health/handicap change and QoL could also be explained by the presence of the wellknown 'response shift phenomena' (58). The presence of a response shift may result in the over- or underestimation of the true changes and lead to challenges in interpreting QoL measures, especially in longitudinal studies (52). The three classical components of the response shift are reconceptualization defined by as a redefinition of QoL, reprioritization defined as a change in the importance attributed to the component domains that constitute QoL, and recalibration defined as a change in a patient's internal measurement standard. Methods of response shift identification are now well-established. However, determining how to integrate the response shift in the interpretation of QoL scores is a true challenge for the next years.

\subsection{Knowledge of quality of life determinants and predictive role of quality of life on health status}

Evidence regarding the determinants of QoL and predictors of mild- and long-term QoL are lacking. Knowledge of which factors are determinants of QoL in this category of patients would assist clinicians in choosing appropriate care intervention. Number of these determinants might be amenable to specific treatment interventions, which may be expected to improve QoL: depression, cognition, access to compensatory techniques, and equipment, etc.

In the same way, predictive factors of long-term disability were also reported in patients presenting severe and chronic diseases: cancer patients $(59,60)$, cardiovascular diseases (61), and MS (62). We can hypothesize that QoL level may provide prognostic information about the evolution of disability in patients with sever motor chronic disability. The identification of early predictors of the evolution of disability status may be useful to identify high-risk patients who require early and more aggressive therapies.

Patient-reported QoL provide additional prognostic information beyond traditional clinical or sociodemographic factors. These findings provide strong support for the integration of QoL into clinical practice, in addition to other standard assessments, and reinforce the importance of incorporating a patient's evaluation of their own QoL level during patient monitoring and the assessment of therapeutic effects (63). Future studies should provide data from longer follow-up times.

\subsection{Quality of life evaluation for individuals with cognitive impairment}

Patients with advanced MS, patients with ALS associated with fronto temporal dementia, and some LIS patients with extended stroke present cognitive impairment (64). One may question the relevance of QoL evaluation results using self reported questionnaires in patients with cognitive impairment. Although, recent studies reported data providing strong arguments to support the conclusion that patients with cognitive dysfunction are reliable and consistent when answering a QoL questionnaire. These works suggested that cognitive dysfunction did not compromise the reliability or validity of the selfreported QoL questionnaires among subjects with cognitive dysfunction and clarify the relevance of using self-reported QoL assessments in clinical practice $(12,65,66)$.

\section{The quality of life of the caregivers}

It is now well-known that caregiving negatively impacts the life of the caregiver (67-69).Caregiving leads to a higher risk of mortality (70) and resulted in a significant and substantial burden, restricted roles and activities, and increased psychosomatic (71), anxious, or depressive symptoms (72), and lower QoL (73).

However, while caregiving was most often thought to be a negative phenomenon, it is increasingly recognized that caregivers also experience subjective gains and satisfaction (74). The caregiving experience can promote a sense of accomplishment, companionship, fulfillment, enjoyment and improved self-esteem. Some families can be brought closer together when someone is in need of care.

Additionally, caregivers' experience, which can be positive or negative, may affect their ability to care and support for the patients. Caregivers have been highlighted as key-actors in the provision of health care, especially regarding their ability to support patients. Caregivers may contribute to the patients' acceptance of treatments. So, considering the caregivers' experience is a noteworthy issue both for the caregivers themselves and indirectly for patients' health. The assessment of caregiver experiences is considered increasingly important with regard to evaluating disease progression, treatment and the management of care provided to patients and evaluating his/her own mental and physical health status. Several groups have published detailed recommendations for QoL assessment that is now being considered increasingly important with regard to evaluating the management of care provided to the caregivers $(75,76)$. Despite the acknowledged need to consider caregiver experience issues, their assessment remains routinely under-utilized. The QoL of relatives and careers is also important and is a potential target for intervention: human aid, technical aid, respite care, and psychological support. The feed-back to caregivers of patient's QoL may help caregivers to cope better with the situation.

There are almost no data about caregivers of patients with severe chronic motor disability (77). 


\section{Conclusion}

Evaluation of QoL in patients with heavy motor handicap is a challenge of major interest, with considerable ethical issues. It needs to use appropriate QoL scales and longitudinal design due to presence of adaptive phenomena to the degree of handicap. Evaluation and longitudinal monitoring of the QoL of people with severe chronic motor disabilities can help to maximize the social and health policies.

\section{References}

1. Simmons Z, Bremer BA, Robbins RA, Walsh SM, Fischer S. Quality of life in ALS depends on factors other than strength and physical function. Neurology. 2000; 55:388-392.

2. Goldstein LH, Atkins L, Leigh PN. Correlates of quality of life in people with motor neuron disease (MND). Amyotroph Lateral Scler Other Motor Neuron Disord. 2002; 3:123-129.

3. Robbins RA, Simmons Z, Bremer BA, Walsh SM, Fischer S. Quality of life in ALS is maintained as physical function declines. Neurology. 2001; 56:442444.

4. Trail M, Nelson ND, Van JN, Appel SH, Lai EC. A study comparing patients with amyotrophic lateral sclerosis and their caregivers on measures of quality of life, depression, and their attitudes toward treatment options. J Neurol Sci. 2003; 209:79-85.

5. Kübler A, Winter S, Ludolph AC, Hautzinger M, Birbaumer N. Severity of depressive symptoms and quality of life in patients with amyotrophic lateral sclerosis. Neurorehabil Neural Repair. 2005; 19:182-193.

6. McDonald ER, Hillel A, Wiedenfeld SA. Evaluation of the psychological status of ventilatory-supported patients with ALS/MND. Palliat Med. 1996; 10:35-41.

7. Sprangers MA, Aaronson NK. The role of health care providers and significant others in evaluating the quality of life of patients with chronic disease: A review. J Clin Epidemiol. 1992; 45:743-760.

8. Nijs J, Inghelbrecht E, Daenen L, Hachimi-Idrissi S, Hens L, Willems B, Roussel N, Cras P, Bernheim J. Long-term functioning following whiplash injury: The role of social support and personality traits. Clin Rheumatol. 2011; 30:927-935.

9. Rousseau M-C, Baumstarck K, Alessandrini M, Blandin V, Billette de Villemeur T, Auquier P. Quality of life in patients with locked-in syndrome: Evolution over a 6-year period. Orphanet J Rare Dis. 2015; 10:88.

10. Mets T, De Deyn PP, Pals P, De Lepeleire J, Vandewoude M, Ventura M, Ivanoiu A, Albert A, Seghers AK; COGNOS group. COGNOS: Care for people with cognitive dysfunction: A national observational study. Alzheimer Dis Assoc Disord. 2013; 27:123-132.

11. Klein M, Menneking H, Spring A, Rose M. Analysis of quality of life in patients with a facial prosthesis. MundKiefer- Gesichtschirurgie MKG. 2005; 9:205-213. (in German)

12. Baumstarck K, Boyer L, Boucekine M, Michel P, Pelletier J, Auquier P. Measuring the quality of life in patients with multiple sclerosis in clinical practice: A necessary challenge. Mult Scler Int. 2013; 2013:1-8.
13. Patrick DL, Deyo RA. Generic and disease-specific measures in assessing health status and quality of life. Med Care. 1989; 27:S217-232.

14. Leplège A, Ecosse E, Verdier A, Perneger TV. The French SF-36 Health Survey: Translation, cultural adaptation and preliminary psychometric evaluation. J Clin Epidemiol. 1998; 51:1013-1023.

15. Coste J. Manual and score interpretation. Medical Outcome Study Short form 36 Item Health Survey. Estem, Paris, France, 2001; p. 156.

16. Lintern TC, Beaumont JG, Kenealy PM, Murrell RC. Quality of Life (QoL) in severely disabled multiple sclerosis patients: Comparison of three QoL measures using multidimensional scaling. Qual Life Res. 2001; 10:371-378.

17. Rousseau M-C, Pietra S, Blaya J, Catala A. Quality of life of ALS and LIS patients with and without invasive mechanical ventilation. J Neurol. 2011; 258:1801-1804.

18. Tramonti F, Bongioanni P, Di Bernardo C, Davitti S, Rossi B. Quality of life of patients with amyotrophic lateral sclerosis. Psychol Health Med. 2012; 17:621-628.

19. Tlili L, Lebib S, Moalla I, Ghorbel S, Bensalah FZ, Dziri C, Aouididi F. Impact of physical activity on the autonomy and the quality of life of patients with spinal cord injury. Ann Readapt Med Phys. 2008; 51:179-183. ( in French)

20. Gilson BS, Gilson JS, Bergner M, Bobbit RA, Kressel S, Pollard WE, Vesselago M. The sickness impact profile. Development of an outcome measure of health care. Am J Public Health. 1975; 65:1304-1310.

21. Kreiter KT, Rosengart AJ, Claassen J, Fitzsimmons BF, Peery S, Du YE, Connolly ES, Mayer SA. Depressed mood and quality of life after subarachnoid hemorrhage. J Neurol Sci. 2013; 335:64-71.

22. Balioussis C, Hitzig SL, Flett H, Noreau L, Craven BC. Identifying and classifying quality of life tools for assessing spasticity after spinal cord injury. Top Spinal Cord Inj Rehabil. 2014; 20:208-224.

23. Power M, Harper A, Bullinger M. The World Health Organization WHOQOL-100: Tests of the universality of Quality of Life in 15 different cultural groups worldwide. Health Psychol. 1999; 18:495-505.

24. Development of the World Health Organization WHOQOL-BREF quality of life assessment. The WHOQOL Group. Psychol Med. 1998; 28:551-558.

25. Lo Coco G, Lo Coco D, Cicero V, Oliveri A, Lo Verso G, Piccoli F, La Bella V. Individual and health-related quality of life assessment in amyotrophic lateral sclerosis patients and their caregivers. J Neurol Sci. 2005; 238:1117.

26. Dajpratham P, Kuptniratsaikul V, Kovindha A, Kuptniratsaikul PS, Dejnuntarat K. Prevalence and management of poststroke spasticity in Thai stroke patients: A multicenter study. J Med Assoc Thai. 2009; 92:1354-1360.

27. Bernheim JL. How to get serious answers to the serious question: "How have you been?": Subjective quality of life (QOL) as an individual experiential emergent construct. Bioethics. 1999; 13:272-287.

28. Bernheim J. Improving the quality of life and survival of cancer patients. Rev Med Liege. 1984; 39:122-126. (in French)

29. Bruno M-A, Bernheim JL, Ledoux D, Pellas F, Demertzi A, Laureys S. A survey on self-assessed well-being in a cohort of chronic locked-in syndrome patients: 
Happy majority, miserable minority. BMJ Open. 2011; $1: \mathrm{e} 000039$.

30. McGee HM, O'Boyle CA, Hickey A, O'Malley K, Joyce $\mathrm{CR}$. Assessing the quality of life of the individual: The SEIQoL with a healthy and a gastroenterology unit population. Psychol Med. 1991; 21:749-759.

31. Hickey AM, Bury G, O'Boyle CA, Bradley F, O'Kelly FD, Shannon W. A new short form individual quality of life measure (SEIQoL-DW): Application in a cohort of individuals with HIV/AIDS. BMJ. 1996; 313:29-33.

32. O'Boyle C, McGee H, Hickey A, Joyce CRB, Browne J, O'Malley K, Hiltbruner B. The schedule for the evaluation of individual quality of life (SEIQoL). Administration Manual. 1993; http://epubs.rcsi.ie/ psycholrep/39/ (accessed Mar 19, 2016).

33. Hecht M, Hillemacher T, Gräsel E, Tigges S, Winterholler M, Heuss D, Hilz MJ, Neundörfer B. Subjective experience and coping in ALS. Amyotroph Lateral Scler Other Motor Neuron Disord. 2002; 3:225231.

34. Chiò A, Gauthier A, Montuschi A, Calvo A, Di Vito N, Ghiglione P, Mutani R. A cross sectional study on determinants of quality of life in ALS. J Neurol Neurosurg Psychiatry. 2004; 75:1597-1601.

35. Bremer BA, Simone A-L, Walsh S, Simmons Z, Felgoise SH. Factors supporting quality of life over time for individuals with amyotrophic lateral sclerosis: The role of positive self-perception and religiosity. Ann Behav Med. 2004; 28:119-125.

36. Foley G, O'Mahony P, Hardiman O. Perceptions of quality of life in people with ALS: effects of coping and health care. Amyotroph Lateral Scler. 2007; 8:164-916.

37. Lou J-S, Reeves A, Benice T, Sexton G. Fatigue and depression are associated with poor quality of life in ALS. Neurology. 2003; 60:122-123.

38. Neudert C, Wasner M, Borasio GD. Patients' assessment of quality of life instruments: A randomised study of SIP, SF-36 and SEIQoL-DW in patients with amyotrophic lateral sclerosis. J Neurol Sci. 2001; 191:103-109.

39. Jenkinson C, Fitzpatrick R, Brennan C, Bromberg $\mathrm{M}$, Swash M. Development and validation of a short measure of health status for individuals with amyotrophic lateral sclerosis/motor neurone disease: The ALSAQ-40. J Neurol. 1999; 246:III16-21.

40. Fischer JS, LaRocca NG, Miller DM, Ritvo PG, Andrews $\mathrm{H}$, Paty D. Recent developments in the assessment of quality of life in multiple sclerosis (MS). Mult Scler. 1999; 5:251-259.

41. McGuigan C, Hutchinson M. The multiple sclerosis impact scale (MSIS-29) is a reliable and sensitive measure. J Neurol Neurosurg Psychiatry. 2004; 75:266269.

42. Simeoni M, Auquier P, Fernandez O, et al. Validation of the Multiple Sclerosis International Quality of Life questionnaire. Mult Scler. 2008; 14:219-230.

43. McKenna SP. Measuring quality of life in schizophrenia. Eur Psychiatry. 1997; 12:267s-274s.

44. Michel P, Baumstarck K, Ghattas B, et al. Multidimensional computerized adaptive short-form quality of life questionnaire developed and validated for multiple sclerosis: The MusiQoL-MCAT. Medicine (Baltimore). 2015; doi: 10.1097/MD.0000000000003068

45. Colloca L, Finniss D. Nocebo effects, patient-clinician communication, and therapeutic outcomes. JAMA. 2012; 307:567-568.
46. Higginson IJ, Carr AJ. Measuring quality of life: Using quality of life measures in the clinical setting. BMJ. 2001; 322:1297-300.

47. Leplège A, Ecosse E, Coste J, Pouchot J, Perneger T. Le questionnaire MOS SF-36: Manuel de l'utilisateur et guide d'interprétation des scores [Internet]. De Boeck Secundair, 2001; https://books.google.fr/books?hl=fr\&lr $=\& i d=I Q A c s u 60 j 7 \mathrm{kC} \&$ oi $=$ fnd $\& p g=P A 7 \& d q=\% 5 \mathrm{BLepl}$ ege $+A,+$ Ecosse $+E,+$ Pouchot $+J,+$ Coste $+J,+$ Perneger + $T V:+M O S+S F 36+q u e s t i o n n a i r e .+$ Manual + and + guideli $n e s+$ for + scores $\% 27+$ interpretation.+ Estem + edition. $+V$ ernouillet $\% 3 B+2001 \&$ ots $=Q t z f A 2 z \quad y Z \& s i g=v G d 4 O k x B$ RsQuSSyUYnwpbnMinNO (accessed Mar 19, 2016).

48. Doble JE, Haig AJ, Anderson C, Katz R. Impairment, activity, participation, life satisfaction, and survival in persons with locked-in syndrome for over a decade: Follow-up on a previously reported cohort. J Head Trauma Rehabil. 2003; 18:435-444.

49. Lulé D, Zickler C, Häcker S, Bruno MA, Demertzi A, Pellas F, Laureys S, Kübler A. Life can be worth living in locked-in syndrome. Prog Brain Res. 2009; 177:339351.

50. Wilson BA, Hinchcliffe A, Okines T, Florschutz G, Fish J. A case study of locked-in-syndrome: Psychological and personal perspectives. Brain Inj. 2011; 25:526-538.

51. Neudert C, Wasner M, Borasio GD. Individual quality of life is not correlated with health-related quality of life or physical function in patients with amyotrophic lateral sclerosis. J Palliat Med. 2004; 7:551-557.

52. Nelson ND, Trail M, Van JN, Appel SH, Lai EC. Quality of life in patients with amyotrophic lateral sclerosis: Perceptions, coping resources, and illness characteristics. J Palliat Med. 2003; 6:417-424.

53. Bruno MA, Pellas F, Schnakers C, Van Eeckhout P, Bernheim J, Pantke KH, Damas F, Faymonville ME, Moonen G, Goldman S, Laureys S. Blink and you live: The locked-in syndrome. Rev Neurol (Paris). 2008; 164:322-335. (in French)

54. Stevens SL, Caputo JL, Fuller DK, Morgan DW. Physical activity and quality of life in adults with spinal cord injury. J Spinal Cord Med. 2008; 31:373-378.

55. Laureys S, Pellas F, Van Eeckhout P, Ghorbel S, Schnakers C, Perrin F, Berré J, Faymonville ME, Pantke KH, Damas F, Lamy M, Moonen G, Goldman S. The locked-in syndrome: What is it like to be conscious but paralyzed and voiceless? Prog Brain Res. 2005; 150:495511.

56. Albrecht GL, Devlieger PJ. The disability paradox: High quality of life against all odds. Soc Sci Med 1982. 1999; 48:977-988.

57. Noble JG, Osborne LA, Jones KH, Middleton RM, Ford DV. Commentary on "disability outcome measures in multiple sclerosis clinical trials". Mult Scler. 2012; 18:1718-1720.

58. Sprangers MA, Schwartz CE. The challenge of response shift for quality-of-life-based clinical oncology research. Ann Oncol. 1999; 10:747-749.

59. Sterzi S, Cesario A, Cusumano G, Corbo G, Lococo F, Biasotti B, Lapenna LM, Magrone G, Dall'armi V, Meacci E, Porziella V, Bonassi S, Margaritora S, Granone P. How best to assess the quality of life in longterm survivors after surgery for NSCLC? Comparison between clinical predictors and questionnaire scores. Clin Lung Cancer. 2013; 14:78-87.

60. Bradley EB, Bissonette EA, Theodorescu D. 
Determinants of long-term quality of life and voiding function of patients treated with radical prostatectomy or permanent brachytherapy for prostate cancer. BJU Int. 2004; 94:1003-1009.

61. Delcourt C, Hackett M, Wu Y, et al. Determinants of quality of life after stroke in China: The ChinaQUEST (QUality Evaluation of Stroke care and Treatment) study. Stroke. 2011; 42:433-438.

62. Baumstarck K, Pelletier J, Butzkueven H, Fernández O, Flachenecker P, Idiman E, Stecchi S, Boucekine M, Auquier P; MusiQoL study group. Health-related quality of life as an independent predictor of long-term disability for patients with relapsing-remitting multiple sclerosis. Eur J Neurol. 2013; 20:907-914, e78-9.

63. Plan2007_2011.pdf. http://social-sante.gouv.fr/IMG/pdf/ plan2007_2011.pdf (accessed Feb 9, 2016).

64. Schnakers C, Majerus S, Goldman S, Boly M, Van Eeckhout P, Gay S, Pellas F, Bartsch V, Peigneux P, Moonen G, Laureys S. Cognitive function in the lockedin syndrome. J Neurol. 2008; 255:323-330.

65. Gold SM, Schulz H, Mönch A, Schulz K-H, Heesen C. Cognitive impairment in multiple sclerosis does not affect reliability and validity of self-report health measures. Mult Scler. 2003; 9:404-410.

66. Marrie RA, Miller DM, Chelune GJ, Cohen JA. Validity and reliability of the MSQLI in cognitively impaired patients with multiple sclerosis. Mult Scler. 2003; 9:621626.

67. Minaya Flores P, Berbis J, Chinot O, Auquier P. Assessing the quality of life among caregivers of patients with gliomas. Neurooncol Pract. 2014; 1:191-197.

68. El-Jawahri AR, Traeger LN, Kuzmuk K, et al. Quality of life and mood of patients and family caregivers during hospitalization for hematopoietic stem cell transplantation. Cancer. 2015; 121:951-959.

69. Caqueo-Urízar A, Gutiérrez-Maldonado J, Miranda-
Castillo C. Quality of life in caregivers of patients with schizophrenia: A literature review. Health Qual Life Outcomes. 2009; 7:84.

70. Schulz R, Beach SR. Caregiving as a risk factor for mortality: The Caregiver Health Effects Study. JAMA. 1999; 282:2215-2219.

71. Carter PA, Chang BL. Sleep and depression in cancer caregivers. Cancer Nurs. 2000; 23:410-415.

72. Kurtz ME, Kurtz JC, Given CW, Given BA. Depression and physical health among family caregivers of geriatric patients with cancer - a longitudinal view. Med Sci Monit. 2004; 10:CR447-56.

73. Kim Y, Given BA. Quality of life of family caregivers of cancer survivors: Across the trajectory of the illness. Cancer. 2008; 112:2556-2568.

74. Cohen CA, Colantonio A, Vernich L. Positive aspects of caregiving: Rounding out the caregiver experience. Int J Geriatr Psychiatry. 2002; 17:184-188.

75. Apolone G, De Carli G, Brunetti M, Garattini S. Health-related quality of life (HR-QOL) and regulatory issues. An assessment of the European Agency for the Evaluation of Medicinal Products (EMEA) recommendations on the use of HR-QOL measures in drug approval. PharmacoEconomics. 2001; 19:187-195.

76. Bottomley A, Jones D, Claassens L. Patient-reported outcomes: Assessment and current perspectives of the guidelines of the Food and Drug Administration and the reflection paper of the European Medicines Agency. Eur J Cancer. 2009; 45:347-353.

77. Ozdilek B, Gunal DI. Motor and non-motor symptoms in Turkish patients with Parkinson's disease affecting family caregiver burden and quality of life. J Neuropsychiatry Clin Neurosci. 2012; 24:478-483.

(Received March 26, 2016; Revised March 29, 2016 ; Accepted March 31, 2016) 